PROFESI (Profesional Islam)

Media Publikasi Penelitian; 2018; Volume 15; No 2.

Website: ejournal.stikespku.ac.id

\title{
Hubungan Kualitas Tidur dan Aktivitas Fisik dengan Tekanan Darah pada Lansia di Posyandu Lansia Desa Setrorejo
}

\author{
Desty Prastika Sari $^{*}$, Dewi Pertiwi Dyah Kusudaryati ${ }^{2}$, Retno Dewi Noviyanti ${ }^{3}$ \\ Prodi S1 Gizi STIKES PKU Muhammadiyah Surakarta \\ *Email: destyp.23@gmail.com
}

\section{Kata Kunci}

Kualitas Tidur, Aktivitas Fisik, Tekanan Darah, Lansia

\begin{abstract}
Abstrak
Peningkatan usia harapan hidup dan penurunan angka fertilitas mengakibatkan populasi penduduk lansia meningkat. Pada usia lanjut tekanan darah akan cenderung tinggi sehingga lansia lebih besar berisiko mengalami hipertensi. Menurut Riskesdas sebanyak 25,8\% penduduk Indonesia menderita hipertensi. Tujuan penelitian ini untuk mengetahui hubungan kualitas tidur dan aktivitas fisik dengan tekanan darah pada lansia di posyandu lansia Desa Setrorejo. Penelitian ini menggunakan jenis penelitian observasional analitik dengan pendekatan cross sectional dengan analisa data menggunakan metode rank spearman. Kualitas tidur diambil menggunakan kuesioner yang berisi kebiasaan tidur selama satu bulan terakhir dan aktivitas fisik diambil menggunakan kuesioner kebiasaan beraktivitas sehari-hari selama tujuh hari terakhir serta tekanan darah diperiksa langsung pada waktu pengukuran kualitas tidur dan aktivitas fisik. Penelitian ini dilakukan pada 63 sampel, berdasarkan karakteristik jenis kelamin sampel yang terbanyak adalah berjenis kelamin perempuan yaitu sebanyak 56 orang (88,9\%). Sampel sebanyak 32 orang $(50,8 \%)$ memiliki kualitas tidur berkategori baik dan sebanyak 34 orang (54\%) memiliki aktivitas fisik berat. Sebanyak 24 orang $(38,1 \%)$ memiliki tekanan darah normal. Ada hubungan kualitas tidur dengan tekanan darah sistolik $(p=0,020)$, ada hubungan kualitas tidur dengan tekanan darah diastolik $(p=0,014)$, ada hubungan aktivitas fisik dengan tekanan tekanan darah sistolik ( $p=0,007)$, dan ada hubungan aktivitas fisik dengan tekanan darah diastolik $(p=0,025)$.
\end{abstract}

\section{The Correlation of Sleep Quality and Physical Activities with Blood Pessure in Elderly at Elderly Posyandu Setrorejo Village}

\section{Keywords}

Sleep Quality, Physical Activity, Blood Pressure, Elderly

\begin{abstract}
The increasing of life expectancy and the decreasing of fertility rate resulted the increase of elderly population. In elderly the blood pressure will tend to be high so that elderly are at the risk of having hypertension. According to Riskesdas as much as $25.8 \%$ of Indonesia's population suffer from hypertension.The aim of this research is to know correlation between sleep quality and physical activity with blood pressure in elderly at posyandu elderly Setrorejo Village. This study used analytic observational with cross sectional approach with data analysis using rank spearman method. Sleep quality was taken by using a questionnaire that contained sleep habits during the last month and physical activity was taken by using the daily activity question questionnaire for the last seven days and blood pressure was examined immediately at the time of sleep quality measurement and physical activity. This study was conducted on 63 samples, based on sex characteristics of the most frequent samples were female 56 people (88.9\%). The sample of 32 people $(50,8 \%)$ had good sleep quality and 34 people (54\%) had heavy physical
\end{abstract}


PROFESI (Profesional Islam)

Media Publikasi Penelitian; 2018; Volume 15; No 2.

Website: ejournal.stikespku.ac.id

activity. A total of 24 people (38.1\%) had normal blood pressure. The relationship of sleep quality with systolic blood pressure $(p=0,020)$, sleep quality relationship with diastolic blood pressure $(p=0,014)$, physical activity relationship with systolic blood pressure $(p=0,007)$, physical activity relation with diastolic blood pressure $(p=0.025)$.

\section{PENDAHULUAN}

Peningkatan usia harapan hidup dan penurunan angka fertilitas mengakibatkan populasi penduduk lanjut usia meningkat. WHO memperkirakan akan terjadi peningkatan proporsi lansia di dunia dari $7 \%$ pada tahun 2020 sampai $23 \%$ pada tahun 2025 (Novitaningtyas, 2014). Pada usia lanjut tekanan darah akan cenderung tinggi sehingga lansia lebih besar berisiko tekanan hipertensi. Hipertensi merupakan tekanan darah melebihi batas normal. Tekanan darah yang normal adalah 120/80 $\mathrm{mmHg}$. Nilai tekanan darah bukanlah nilai tekanan darah baku yang menunjukkan seseorang mengalami hipertensi, tergantung pada aktivitas dan emosional seseorang (Nurrahmani, 2012).

Hipertensi merupakan salah satu penyakit degeneratif yang perlu diwaspadai bagi kesehatan karena tidak terdapat tanda-tanda atau gejala yang dapat dilihat dari luar, akan tetapi dapat menyebabkan komplikasi pada organ tertentu (WHO, 2011). Hipertensi merupakan gangguan sistem peredaran darah yang dapat dicegah, namun dapat menimbulkan berbagai macam komplikasi.

Berbagai studi menunjukkan bahwa hipertensi meningkatkan risiko kematian dan penyakit seperti penyakit jantung, stroke, dan gagal ginjal (Noviyanti, 2015). Menurut data WHO dalam Non Communicable Disease Country Profiles prevalensi didunia pada usia $>25$ tahun mencapai $38,4 \%$. Prevalensi Indonesia lebih besar jika dibandingkan dengan Bangladesh, Korea, Nepal, dan Thailand (Krishman, dkk, 2013). Sebanyak $25,8 \%$ penduduk Indonesia menderita hipertensi dengan jumlah 65.048.110 jiwa. Hasil data RISKESDAS Jawa Tengah tahun 2014, dari 5.313.289 orang yang diperiksa $10,84 \%$ terdeteksi memiliki tekanan darah tinggi (Dinas Kesehatan Jawa Tengah, 2014). Prevalensi hipertensi Kabupaten Wonogiri pada tahun 2013 sebesar 49,5\%, dimana hipertensi merupakan masalah kesehatan prioritas dilihat dari tingginya kasus di wilayah ini dan merupakan penyakit tidak menular tertinggi setiap tahunnya (Riskesdas, 2013).

Prevalensi hipertensi menurut Pinson (2009) semakin meningkat sesuai peningkatan usia. Hipertensi lebih banyak menyerang setengah baya pada usia 55-64 tahun. Setelah umur 69 tahun prevalensi hipertensi meningkat sampai 50\%. Menurut Depkes (2013) prevalensi lansia yang menderita hipertensi di Indonesia tahun 2011 pada kelompok usia 45-64 tahun mencapai $4,02 \%$ dan pada kelompok usia $>65$ tahun mencapai angka $5,17 \%$. Hipertensi termasuk penyakit multifaktoral yang dipengaruhi oleh berbagai faktor yaitu keturunan, jenis kelamin, umur, ras, perilaku merokok, obesitas, stres, asupan zat gizi, aktivitas fisik dan komplikasi (Martuti, 2009)

Tujuan penelitian ini untuk mengetahui hubungan kualitas tidur dan aktivitas fisik dengan tekanan darah pada lansia di posyandu lansia Desa Setrorejo

\section{METODE PENELITIAN}

Jenis penelitian ini menggunakan desain penelitian observasional analitik dengan pendekatan cross sectional dengan teknik pengambilan sampel simpel random sampling diperoleh sampel sebanyak 63 orang lansia diposyandu lansia Desa Setrorejo. Penelitian ini dilakukan pada bulan Februari 2017.

Penilaian kualitas tidur dan aktivitas fisik dilakukan dengan melakukan wawancara kuesioner kepada 63 sampel dan nilai tekanan darah didapatkan dengan cara pengukuran tekanan darah dengan menggunakan alat sphygmonanometer air raksa dan jarum dibantu oleh petugas kesehatan kelurahan. Data yang telah diperoleh selanjutnya diolah dengan menggunakan program komputer SPSS Statistik 17.0 dengan uji korelasi menggunakan Rank Spearman. 


\section{HASIL DAN PEMBAHASAN}

\subsection{Umur Sampel}

Umur lebih dari 40 tahun mempunyai risiko terkena hipertensi lebih tinggi karena pada usia tersebut mengalami penurunan fungsi fisiologis sehingga kemampuan jantung untuk memompa darah berkurang dan terjadi penumpukan racun pada otot pembuluh darah (Anggraini, dkk, 2009).

Tabel 1. Distribusi Frekuensi Sampel Berdasarkan Umur

\begin{tabular}{ccc}
\hline $\begin{array}{c}\text { Kategori Tekanan } \\
\text { Darah }\end{array}$ & Frekuensi & $\begin{array}{c}\text { Persentase } \\
(\%)\end{array}$ \\
\hline Rendah & 13 & 20,6 \\
Normal & 24 & 38,1 \\
Pre Hipertensi & 12 & 19 \\
Hipertensi 1 & 11 & 17,5 \\
Hipertensi 2 & 3 & 4,8 \\
\hline Total & 63 & 100 \\
\hline
\end{tabular}

Sumber : Data Primer Diolah 2017

Berdasarkan tabel 1, hasil penelitian menunjukkan sampel paling banyak berusia 65-69 tahun sebanyak 32 sampel $(50,8 \%)$. Umur sampel ratarata 66 tahun $\pm 3,37$.

\subsection{Jenis Kelamin Sampel}

Perempuan memiliki risiko hipertensi yang kecil pada masa sebelum menopause. Pada masa menopause wanita tidak dilindungi oleh hormon esterogen yang berfungsi untuk meningkatkan kadar High Density Lipoprotein (HDL). Kolesterol HDL dengan kadar yang tinggi menjadi faktor pelindung untuk mencegah terjadinya proses atherosklerosis. Pada masa lanjut usia produksi estrogen akan menurun sehingga tidak dapat meningkatkan kadar HDL dan menyebabkan lansia perempuan akan mengalami hipertensi (Anggraini, dkk, 2009).

Distribusi frekuensi sampel berdasarkan jenis kelamin dapat dilihat berdasarkan tabel 2 berikut :

Tabel 2. Distribusi Frekuensi SampelBerdasarkan Jenis Kelamin

\begin{tabular}{ccc}
\hline Jenis Kelamin & Frekuensi & Persentase (\%) \\
\hline Laki-laki & 7 & 11,1 \\
Perempuan & 56 & 88,9 \\
\hline Total & 63 & 100 \\
\hline
\end{tabular}

Sumber : Data Primer Diolah 2017
Berdasarkan jenis kelamin sampel terbanyak adalah berjenis kelamin perempuan yaitu sebanyak 56 orang $(88,9 \%)$

\subsection{Tekanan Darah Sampel}

Tekanan darah adalah tekanan yang ditimbulkan oleh darah pada seluruh permukaan dinding pembuluh darah. Tekanan darah ditentukan oleh jumlah darah yang dipompa dari jantung ke seluruh organ dan jaringan tubuh, serta daya tahan dinding pembuluh arteri (Anggraini, dkk, 2009).

Distribusi frekuensi sampel berdasarkan kategori tekanan darah dapat dilihat berdasarkan tabel 3 berikut :

\section{Tabel 3. Distribusi Frekuensi Kategori} Tekanan Darah

\begin{tabular}{ccc}
\hline Umur & Frekuensi & Persentase $(\%)$ \\
\hline $60-64$ & 21 & 33,3 \\
$65-69$ & 32 & 50,8 \\
$70-74$ & 10 & 15,9 \\
\hline Total & 63 & 100
\end{tabular}

Sumber : Data Primer Diolah 2017

Berdasarkan tabel 3 diketahui bahwa kategori tekanan darah paling banyak berada pada tekanan darah normal yaitu sebanyak 24 orang $(38,1 \%)$.

Tekanan darah normal sangat dibutuhkan untuk mengalirkan darah ke seluruh tubuh, yaitu mengangkut oksigen dan zat-zat nutrisi yang penting untuk tubuh.Meningkatnya tekanan darah berkaitan dengan kerja organ jantung yang memompa lebih kuat sehingga volume cairan yang mengalir setiap detik bertambah besar, menebal, dan kakunya arteri besar yang dapat terjadi karena penyumbatan pembuluh arteri (arteriosclerosis), dan kelainan fungsi ginjal sehingga tidak mampu membuang sejumlah garam dan air dari dalam tubuh (Martuti, 2009).

Tabel 4. Distribusi Frekuensi

Tekanan Darah Sistolik

\begin{tabular}{ccc}
\hline Tekanan Darah & Frekuensi & Persentase (\%) \\
\hline$<120 \mathrm{mmHg}$ & 14 & 22,2 \\
$120-139 \mathrm{mmHg}$ & 36 & 57,1 \\
$140-159 \mathrm{mmHg}$ & 9 & 14,3 \\
$>160 \mathrm{mmHg}$ & 4 & 6,4 \\
Total & 63 & 100
\end{tabular}

Sumber : Data Primer Diolah 2017 
Berdasarkan tabel 4 diketahui tekanan darah sistolik paling banyak berada pada angka 120 $139 \mathrm{mmHg}$ sebanyak 36 orang $(57,1 \%)$. Tinggi rendahnya tekanan darah dapat ditentukan oleh tekanan darah sistolik yaitu tekanan darah paling tinggi ketika jantung berkerut memompa darah kedalam arteri (Muhammadun, 2010).

Untuk mengetahui distribusi frekuensi tekanan darah diastolik dapat dilihat pada tabel 5 berikut.

Tabel 5. Distribusi Frekuensi Tekanan Darah Diastolik

\begin{tabular}{ccc}
\hline $\begin{array}{c}\text { Tekanan Darah } \\
(\mathrm{mmHg})\end{array}$ & Frekuensi & $\begin{array}{c}\text { Persentase } \\
(\%)\end{array}$ \\
\hline$<60$ & 0 & 0 \\
$61-90$ & 48 & 76,2 \\
$>91$ & 15 & 23,8 \\
Total & 63 & 100
\end{tabular}

Sumber : Data Primer Diolah 2017

Tekanan darah diastolik yaitu tekanan darah saat jantung istirahat diantara dua denyutan (Muhammadun, 2010).Berdasarkan tabel 5 diketahui tekanan darah diastolik paling banyak pada angka $61-90 \mathrm{mmHg}$ sebanyak 48 orang $(76,2 \%)$.

\subsection{Kualitas Tidur}

Distribusi frekuensi sampel berdasarkan kualitas tidur dapat dilihat berdasarkan tabel 6 berikut :

Tabel 6. Distribusi Frekuensi berdasarkan Kualitas Tidur

\begin{tabular}{ccc}
\hline Kualitas Tidur & Frekuensi & Persentase \% \\
\hline Baik & 32 & 50,8 \\
Buruk & 31 & 49,2 \\
Total & 63 & 100 \\
\hline
\end{tabular}

Sumber : Data Primer Diolah 2017

Penelitian ini diperoleh hasil yaitu kualitas tidur sampel hampir sama antara kualitas baik dan buruk yaitu memiliki selisih yang sangat kecil, dimana kualitas tidur baik sebanyak 32 orang $(50,8 \%)$ dan kualitas tidur buruk sebanyak 31 orang $(49,2 \%)$. Kualitas tidur merupakan fenomena yang sangat kompleks yang melibatkan berbagai domain antara lain, penilaian terhadap lama tidur, gangguan tidur, masa latensi tidur, disfungsi tidur pada siang hari, efisiensi tidur, kualitas tidur dan penggunaan obat tidur. Jadi apabila salah satu dari 7 domain tersebut terganggu maka akan mengakibatkan terjadinya penurunan kualitas tidur (Indarwati, 2012).

\subsection{Aktivitas Fisik}

Distribusi frekuensi sampel berdasarkan aktivitas fisik dapat dilihat berdasarkan tabel 7berikut :

Tabel 7. Distribusi Frekuensi berdasarkan Aktivitas Fisik

\begin{tabular}{ccc}
\hline Aktivitas Fisik & Frekuensi & Persentase \\
\hline Berat & 34 & 53,96 \\
Sedang & 29 & 46,04 \\
Total & 63 & 100 \\
\hline
\end{tabular}

Sumber : Data Primer Diolah 2017

Berdasarkan tabel 7, diketahui lansia paling banyak melakukan aktivitas fisik beratsebanyak 34 orang (53,96\%). Aktivitas fisik juga dapat menurunkan risiko penyakit diabetes, hipertensi dan penyakit jantung koroner. Selain itu, aktivitas fisik juga bermanfaat fisiologis, psikologi maupun sosial, aktivitas fisik dapat meningkatkan kapasitas kekuatan, flexibilitas dan keseimbangan (Kowalski, 2010).

Seseorang dengan aktivitas fisik yang kurang, memiliki kecenderungan 30-50\% terkena hipertensi daripada mereka yang aktif melakukan kegiatan. Peningkatan intensitas akitivitas fisik, 30-45 menit per hari, penting dilakukan sebagai strategi untuk pencegahan dan pengelolaan hipertensi. Aktivitas fisik yang mampu membakar 800-1000 kalori akan meningkatkan High Density Lipoprotein (HDL) sebesar $4,4 \mathrm{mmHg}$ (Santoso, 2013)

\subsection{Hubungan Kualitas Tidur dengan Tekanan Darah Sisitolik}

Kualitas tidur yang buruk atau kebiasaan durasi tidur yang pendek dapat dihubungkan dengan peningkatan tekanan darah. Ketidak cukupan kuantitas dan kualitas tidur dapat merusak memori dan kemampuan kongnitif. Bila hal ini berlanjut selama bertahun-tahun, akan berdampak pada tekanan darah tinggi, serangan jantung, stroke hingga masalah psikologi (Havisa, 2014) 
PROFESI (Profesional Islam)

Media Publikasi Penelitian; 2018; Volume 15; No 2.

Website: ejournal.stikespku.ac.id

Tabel 8. Hasil Uji Hubungan Kualitas Tidur dengan Tekanan Darah Sistolik

\begin{tabular}{ccccc}
\hline Variabel & $\begin{array}{c}\text { Rata- } \\
\text { rata }\end{array}$ & $\pm \mathrm{SD}$ & $\mathrm{rs}$ & $\mathrm{p}^{*}$ \\
\hline $\begin{array}{l}\text { Kualitas } \\
\text { Tidur }\end{array}$ & 5,81 & 2,735 & 0,292 & 0,020 \\
Tekanan & 125,06 & 17,117 & & \\
$\quad \begin{array}{l}\text { Darah } \\
\text { sistolik }\end{array}$ & & & & \\
*Rank Spearman & & &
\end{tabular}

Pada penelitian ini terdapat hubungan antara kualitas tidur dengan tekanan darah sistolik dengan nilai $p=0,020$ dan nilai Correlation Coefficient 0,292. Rata-rata kualitas tidur $5,81 \pm 2,735$ dan rata-rata tekanan darah sistolik $125,06 \pm 17,117 \mathrm{mmHg}$.

\subsection{Hubungan Kualitas Tidur dengan Tekanan Darah Sisitolik}

Pada kondisi gangguan tidur, tubuh cenderung memiliki laju metabolisme yang tinggi oleh karena itu dibutuhkan banyak glukosa sebagai bahan bakar pembentuk energi. Hormon lain yang dikeluarkan oleh hipotalamus yaitu vasopressin, hormon ini memiliki fungsi utama meningkatkan reabsorbsi air di tubulus distal dan tubulus kolektivus renal untuk kembali ke dalam darah yang akan membantu mengatur volume cairan tubuh. Jika vasopressin meningkat karena rangsangan oleh hipotalamus maka terjadi peningkatan reabsorbsi $\mathrm{H}_{2} \mathrm{O}$ yang akan menyebabkan peningkatan volume plasma yang akan meningkatkan curah jantung sehingga tekanan darah meningkat (Astuti, 2016).

Tabel 9 Hasil Uji Hubungan Kualitas Tidur dengan Tekanan Darah diastolik

\begin{tabular}{ccccc}
\hline Variabel & $\begin{array}{c}\text { Rata- } \\
\text { rata }\end{array}$ & $\pm \mathrm{SD}$ & rs & $\mathrm{p}^{*}$ \\
\hline $\begin{array}{c}\text { Kualitas } \\
\text { tidur }\end{array}$ & 5,81 & 2,735 & 0,308 & 0,014 \\
$\begin{array}{c}\text { Tekanan } \\
\text { Darah }\end{array}$ & 85,87 & 10,416 & & \\
$\begin{array}{l}\text { diastolic } \\
\text { * Rank Spearman }\end{array}$ & & & \\
\hline
\end{tabular}

Pada penelitian ini terdapat hubungan antara kualitas tidur dengan tekanan darah diastolik dengan nilai $\mathrm{p}=0,014$ dan nilai Correlation
Coefficient 0,308. Rata-rata kualitas tidur $5,8 \pm 85,87$ dan rata-rata tekanan darah diastolik $85,87 \pm 10,416 \mathrm{mmHg}$.

Pada penelitian ini terdapat hubungan kualitas tidur dengan tekanan darah sistolik maupun diastolik. Hasil tersebut sesuai dengan penelitian yang dilakukan Asmarita (2013) dengan sampel pasien hipertensi, menyatakan bahwa ada hubungan antara kualitas tidur dengan tekanan darah pasien hipertensi dengan nilai $p=$ 0,009. Menurut Gangwisch (2006), saat seseorang mengalami gangguan tidur, maka hipotalamus akan mengaktifkan 2 sumbu yaitu medulla adrenal sympatic dan hipotalamic pituitary adrenal-axis.

Pada saat stressor datang disebabkan oleh gangguan tidur, maka hormon norepinfrin dan epinefrin disekresikan oleh kelenjar medulla adrenal dan efek dari perangsangannya yaitu langsung pada organ-organ spesifik seperti pembuluh darah dan jantung. Kedua hormon tersebut langsung membuat pembuluh darah setiap jaringan akan mengalami vasokontriksi sehingga membuat tahanan perifer meningkat yang akhirnya dapat meningkatkan tekanan darah.

\subsection{Hubungan Aktivitas Fisik dengan Tekanan Darah Sistolik}

Aktivitas fisik sangat penting peranannya terutama bagi lansia. Dengan melakukan aktivitas fisik, maka lansia dapat mempertahankan bahkan meningkatkan derajat kesehatannya. Namun, karena keterbatasan fisik yang dimiliki lansia akibat pertambahan usia serta perubahan dan penurunan fungsi fisiologis, maka lansia memerlukan beberapa penyesuaian dalam melakukan aktivitas fisik sehari-hari (Fatimah, 2010).

Tabel 10. Hasil Uji Korelasi Aktivitas Fisik dengan Tekanan Darah Sistolik

\begin{tabular}{ccccc}
\hline Variabel & $\begin{array}{c}\text { Rata- } \\
\text { rata }\end{array}$ & $\pm \mathrm{SD}$ & rs & $\mathrm{P}^{*}$ \\
\hline Aktivitas & 2957,16 & 768,24 & - & 0,007 \\
$\quad$ Fisik & & & 0,335 & \\
$\begin{array}{c}\text { Tekanan } \\
\text { Darah }\end{array}$ & 125,06 & 17,117 & & \\
sistolik & & & & \\
\hline
\end{tabular}

*Rank Spearman 
PROFESI (Profesional Islam)

Media Publikasi Penelitian; 2018; Volume 15; No 2.

Website: ejournal.stikespku.ac.id

Berdasarkan hasil uji korelasi diketahui bahwa nilai $p=0,007$, menyatakan bahwa ada hubungan yang signifikan antara aktivitas fisik dengan tekanan darah sistolik lansia dengan nilai Correlation Coefficient $-0,335$ yang artinya semakin tinggi aktivitas fisik maka semakin rendah tekanan darah. Rata-rata skor aktivitas fisik $2957,16 \pm 768,24$ dan rata-rata tekanan darah sistolik 125,06 $\pm 17,117 \mathrm{mmHg}$.

Tabel 11. Hasil Uji Korelasi Aktivitas Fisik dengan Tekanan Darah Diastolik

\begin{tabular}{ccccc}
\hline Variabel & $\begin{array}{c}\text { Rata- } \\
\text { rata }\end{array}$ & \pm SD & rs & $\mathrm{P}^{*}$ \\
\hline Aktivitas & 2957,16 & 768,24 & - & 0,025 \\
$\quad$ Fisik & & & 0,282 & \\
$\begin{array}{l}\text { Tekanan } \\
\text { Darah }\end{array}$ & 85,87 & 10,416 & & \\
$\quad$ & & & \\
diastolic & & & & \\
* Rank Spearman & & &
\end{tabular}

Berdasarkan hasil uji korelasi diketahui bahwa nilai $\mathrm{p}=0,025$, menyatakan bahwa ada hubungan yang signifikan antara aktivitas fisik dengan tekanan darah diastolik lansia dengan nilai Correlation Coefficient -0,282 yang artinya semakin tinggi aktivitas fisik maka semakin rendah tekanan darah. Rata-rata skor aktivitas fisik $2957,16 \pm 768,24$ dan rata-rata tekanan darah diastolik 85,87 $\pm 10,416 \mathrm{mmHg}$.

Pada penelitian ini dapat disimpulkan bahwa terdapat hubungan aktivitas fisik dengan tekanan darah sistolik maupun diastolik dengan nilai correlation coefficient negatif. Pada uji korelasi tersebut terdapat hubungan yang berbanding terbalik yaitu apabila semakin meningkat aktivitas fisik maka tekanan darah akan menurun.

Penelitian ini sejalan dengan penelitian yang dilakukan Paruntu dan Rumagit (2015) yaitu ada hubungan yang bermakna antara aktivitas fisik dengan tekanan darah pada lansia. Hasil penelitian tersebut sesuai dengan penelitian Budiono (2015) pada lanjut usia di Desa Ngabean, Kebumen dengan hasil penelitian ada hubungan antara aktivitas fisik dengan status kesehatan hipertensi pada lanjut usia.

Aktivitas fisik yang terukur, benar dan teratur dapat mengurangi risiko terjadinya penyakit tidak menular (PTM) dan dapat meningkatkan derajat kesehatan dan kebugaran jasmani (Wardani \&Roosita, 2008). Menurut Kushartanti (2006), aktivitas fisik dapat menyebabkan seseorang menjadi lebih tenang, lebih kuat menghadapi stress dan memiliki indeks masa tubuh yang cenderung normal.

Aktivitas fisik juga melambatkan arterosklerosis dan menurunkan risiko serangan jantung dan stroke dimana aktivitas fisik dapat meningkatkan aliran darah ke jantung, menjaga elastisitas arteri dan fungsi arterial (Kowalski, 2010). Menurut Indarwati (2012) aktivitas fisik sedang hingga tinggi dapat mencegah kenaikan tekanan darah yang sangat tinggi dimana dampak lebih parahnya terkena stroke. Selain itu analisa menyebutkan bahwa berjalan kaki menurunkan tekanan darah pada orang dewasa sekitar $2 \%$ (Fitriana, 2007).

\section{SIMPULAN}

1. Kualitas tidur lansia cenderung hampir sama yaitu kualitas tidur baik $(50,8 \%)$ dan kualitas tidur buruk $(49,2 \%)$

2. Sebagian besar lansia di posyandu lansia Desa Setrorejo Baturetno Wonogiri melakukan aktivitas fisik berat $(53,96 \%)$.

3. Sebagian besar lansia di posyandu lansia Desa Setrorejo Baturetno Wonogiri memiliki kategori tekanan darah normal $(38,1 \%)$.

4. Ada hubungan yang signifikan antara kualitas tidur dengan tekanan darah sistolik $(p=0,020)$ dan diastolik $(p=0,014)$ pada lansia di Posyandu Lansia Desa Setrorejo.

5. Ada hubungan yang signifikan antara aktivitas fisik dengan tekanan darah sistolik $(\mathrm{p}=0,007)$ dan diastolik $(\mathrm{p}=0,025)$ pada lansia di Posyandu Lansia Desa Setrorejo.

\section{REFERENSI}

Anggraini, Ade Dian. Waren, Annes. Situmorang, Eduward. Asputra, Hendra. Siahaan, Sylvia Sagita. 2009. Faktor-Faktor Yang Berhubungan dengan Kejadian Hipertensi Pada Pasien Yang Berobat di Poliklinik Dewasa Puskesmas Bangkinang Periode Januari Sampai Juni 2008. Pekan baru Riau: Faculty of Medicine, Universitas Riau. Jurnal Kesehatan Masyarakat. 
PROFESI (Profesional Islam)

Media Publikasi Penelitian; 2018; Volume 15; No 2.

Website: ejournal.stikespku.ac.id

Asmarita, I. 2013. Hubungan antara Kualitas Tidur dengan Tekanan Darah Pada Pasien Hipertensi di Rumah Sakit Umum Daerah Karanganyar. Skripsi. Surakarta : UMS

Astuti, WK. 2016. Hubungan Aktivitas Fisik dengan Tekanan Darah pada Lansia di Posyandu Padukuhan Medari Gede Caturharjo Seleman Yogyakarta. Skripsi. Yogyakarta: STIKES Jendral Achmad Yani.

Budiono. 2015. Hubungan Antara Aktifitas Fisik dengan Status Kesehatan Hipertensi di Desa Ngabean, Kecamatan, Mirit, Kabupaten Kebumen. Skripsi. Kebumen : STIKES Muhammadiyah Gombong

Depkes. 2013. Riset Kesehatan Dasar. Jakarta: Badan Penelitian dan Pengembangan Kesehatan Kementrian Kesehatan RI.

Dinkes Provinsi Jawa Tengah. 2014. Buku Profil Kesehatan Provinsi Jawa Tengah Tahun 2013. Semarang: Dinkes Provinsi Jawa Tengah.

Fatimah. 2010. Gizi Usia Lanjut. Jakarta : Erlangga

Fitriana, N. 2007. Hipetensi pada Lansia. Jakarta : Erlangga

Gangwich, J. 2006. Short Sleep Duration as a Risk Factor for Hypertension. Analyses of The First National Health and Nutrition Examination Survey. American : Heart Association.

Havisa, Riska. 2014. Hubungan Kualitas Tidur dengan Tekanan Darah pada Usia Lanjut di Posyandu Lansia Dusun Jelapan Sindumartani Ngemplak Sleman Yogyakarta. Jurnal Keperawatan Komunitas.

Indarwati, Nova. 2012. Hubungan antara Kualitas Tidur Mahasiswa yang
Mengikuti UKM dan Tidak Mengikuti UKM pada Mahasiswa Reguler Fakultas Ilmu Keperawatan.Skripsi. Depok: Fakultas Ilmu Keperawatan, Universitas Indonesia.

Kowalski, R. 2010. Terapi Hipertensi. Bandung: Mizan Pustaka

Krishnan, A, Garg, R, Kahadaliyanage, A. 2013.Hypertension in the sount-east asian region : an overview'.Journal Regional Health Forumvol. 17, no.1, hlm.7-14.

Kushartanti. 2006. Pengaruh latihan range of motion (ROM) terhadap fleksibilitas sendi pada lansia di Panti Wreda Wening Wardoyo Ungaran.Jurnal Media Ners. 1:5-7.

Martuti. 2009. Merawat dan Menyembuhkan Hipertensi. Bantul: Kreasi Wacana

Muhammadun. 2010. Hidup Bersama Hipertensi. Yogyakarta: In Books

Novitaningtyas, T. 2014. Hubungan Karakteristik (Umur, Jenis Kelamin, Tingkat Pendidikan) dan Aktivitas Fisik dengan Tekanan Darah pada Lansia di Kelurahan Makam Haji Kecamatan Kartasura Kabupaten Sukoharjo. Skripsi. Surakarta: UMS.

Noviyanti. 2015. Hipertensi Kenali, Cegah \& Obati. Yogyakarta: Notebook

Nurrahmani, U. 2012. Stop Hipertensi. Yogyakarta: Familia.

Paruntu, OL \& Rumangit, FA. 2015. Hubungan Aktivitas Fisik, Status Gizi, dan Hipertensi pada Pegawai di Wilayah Kecamata Tomoton Utara. Jurnal Gizi DO. Vol. 7 No. 1

Pinson, R. 2009. Awas Stroke. Yogyakarta : CV. Adi Offset 
PROFESI (Profesional Islam) Media Publikasi Penelitian; 2018; Volume 15; No 2.

Website: ejournal.stikespku.ac.id

Riskesdas. 2013. Badan Penelitian dan Pengembangan Kesehatan Kementrian Kesehatan RI. Jakarta

Santoso, AP. 2013. Hubungan Antara Aktivitas Fisik dan Asupan Magnesium dengan Tekanan Darah pada Penderita Hipertensi Rawat Jalan RSUD Dr. Moewardi di Surakarta. Skripsi. Surakarta: UMS.
Wardani, NEJ. \& K. Roosita. 2008. Aktivitas Fisik, Asupan Energi dan Produktivitas Kerja Pria Dewasa: Studi Kasus di Perkebunan Teh Malabar PTPN VIII Bandung, Jawa Barat. Jurnal Gizi dan Pangan, 3 (2), hal. 71-78.

World Health Organization. 2011. Global Status Report on Noncommunicable Diseases 2010. Geneva. 